\title{
The Niche Component Periostin Is Produced by Cancer-Associated Fibroblasts, Supporting Growth of Gastric Cancer through ERK Activation
}

\author{
Yoshinao Kikuchi, ${ }^{*}$ Akiko Kunita, ${ }^{*}$ Caname Iwata, ${ }^{\dagger}$ Daisuke Komura, ${ }^{*}$ Takashi Nishiyama, ${ }^{\ddagger}$ Kazuhiro Shimazu, ${ }^{*}$ \\ Kimiko Takeshita, ${ }^{*}$ Junji Shibahara, ${ }^{*}$ Isao Kii, ${ }^{\ddagger}$ Yasuyuki Morishita, ${ }^{* \dagger}$ Masakazu Yashiro, ${ }^{\S}$ Kosei Hirakawa, ${ }^{\S}$ Kohei Miyazono, \\ Akira Kudo, ${ }^{\ddagger}$ Masashi Fukayama, ${ }^{*}$ and Takeshi G. Kashima*
}

From the Departments of Pathology* and Molecular Pathology, ${ }^{\dagger}$ Graduate School of Medicine, University of Tokyo, Tokyo; the Department of Biological Information, ${ }^{\ddagger}$ Tokyo Institute of Technology, Yokohama; and the Department of Surgical Oncology, ${ }^{\S}$ Medical School, Osaka City University, Osaka, Japan

\author{
Accepted for publication \\ November 13, 2013. \\ Address correspondence to \\ Masashi Fukayama, M.D., Ph.D., \\ 7-3-1, Hongo, Bunkyo-ku, \\ Tokyo, 113-0033, Japan \\ E-mail: mfukayama-tky@umin. \\ ac.jp.
}

\begin{abstract}
Overexpression of periostin (POSTN), an extracellular matrix protein, has been observed in several cancers. We investigated the importance of POSTN in gastric cancer. Genome-wide gene expression analysis using publicly available microarray data sets revealed significantly high POSTN expression in cancer tissues from stage II-IV gastric cancer, compared with background normal tissues. The POSTN/ vimentin mRNA expression ratio was highly associated with gene groups that regulate the cell cycle and cell proliferation. IHC showed that periglandular POSTN deposition, comprising linear deposition abutting the glandular epithelial cells in normal mucosa, disappeared during intestinal gastric cancer progression. Stromal POSTN deposition was also detected at the invasive front of intestinal-type and diffuse-type cancers. In situ hybridization confirmed POSTN mRNA in cancer-associated fibroblasts, but not in tumor cells themselves. POSTN enhanced the in vitro growth of OCUM-2MLN and OCUM-12 diffuse-type gastric cancer cell lines, accompanied by the activation of ERK. Furthermore, coinoculation of gastric cancer cells with POSTN-expressing NIH3T3 mouse fibroblast cells facilitated tumor formation. The OCUM-2MLN orthotopic inoculation model demonstrated that tumors of the gastric wall in Postn ${ }^{-/-}$mice were significantly smaller than those in wild-type mice. Ki-67 and p-ERK positive rates were both lower in Postn ${ }^{-/-}$mice. These findings suggest that POSTN produced by cancerassociated fibroblasts constitutes a growth-supportive microenvironment for gastric cancer. (Am J Pathol 2014, 184: 859-870; http://dx.doi.org/10.1016/j.ajpath.2013.11.012)
\end{abstract}

The local microenvironment, or niche, plays important roles both in normal tissue maintenance and in cancer development and progression. Extracellular matrix (ECM), a major niche component, is believed to change quantitatively or qualitatively in normal, primary cancer, and metastatic niches. Malanchi et al, ${ }^{1}$ using the MMTV-PyMT mouse breast cancer model, recently demonstrated that periostin (POSTN; alias osteoblast-specific factor 2) plays a primary role in spontaneous metastasis to the lung as ECM of the metastatic niche. POSTN, which is expressed by fibroblasts in normal tissue and in the stroma of the primary tumor, is necessary for cancer stem cell maintenance.

Our research group originally cloned and characterized POSTN, a 90-kDa secreted matricellular protein and a member of the fasciclin (Fas) family. ${ }^{2,3}$ POSTN comprises an aminoterminal EMI domain, a tandem repeat of four Fas I domains, and a carboxyl-terminal domain including a heparinbinding site at its $\mathrm{C}$-terminal end. ${ }^{4}$ POSTN has been regarded as regulating fibrillogenesis in tissue subjected to mechanical

Supported in part by the Ministry of Education, Culture, Sports, Science and Technology grants 18790238 (T.G.K.) and 20249022 (M.F.) and a Research Fellowships grant from the Yasuda Medical Foundation for Young Scientists, Japan (Y.K.).

Y.K. and A.K. contributed equally to this work.

Disclosures: None declared.

Current address of D.K., Department of Genomic Pathology, Medical Research Institute, Tokyo Medical and Dental University, Tokyo, Japan; of T.G.K., Histopathology Department, Nuffield Orthopaedic Centre, Oxford, UK. 
stress, such as the endocardium, fascia, periosteum, articular surface, and periodontal ligament. ${ }^{4}$ POSTN has also been recognized as playing a key role in tissue repair. Our research group has previously shown that POSTN is expressed by myofibroblasts and that it regulates tissue repair processes in myocardial infarction ${ }^{5}$ and wound healing. ${ }^{6}$ POSTN is regarded as an interventional molecular target for myocardial infarction therapy. ${ }^{7}$ In neoplastic lesions, overexpression of POSTN has been identified in various cancers, including those of the lung (non-small-cell subtypes), ${ }^{8}$ ovary, ${ }^{9}$ breast, ${ }^{10,11}$ colon, ${ }^{12,13}$ pancreas, ${ }^{14-17}$ bile duct, ${ }^{18}$ and head and neck. ${ }^{19}$ However, expression and function of POSTN in gastric cancer, the second most common cause of cancer death worldwide, ${ }^{20}$ have not been studied sufficiently, ${ }^{21,22}$ especially with respect to the two distinctive histological groups, the intestinal and diffuse types. ${ }^{23}$ The morphology, molecular and genetic background, and clinical features of the two subtypes differ completely. $^{24}$

In the present study, we investigated the expression and function of POSTN in gastric cancer. First, we evaluated POSTN expression in normal and neoplastic stomach using both bioinformatics and an extensive tissue sample examination to clarify the cell types that predominantly produce POSTN. Next, we examined the function of POSTN using POSTN-producing fibroblasts and an orthotopic inoculation model of diffuse-type gastric cancer in Postn ${ }^{-1-}$ mice. Our results demonstrated that POSTN is overexpressed by cancer-associated fibroblasts (CAFs) and suggested that POSTN constitutes the primary tumor niche by supporting cancer cell proliferation through ERK signaling pathway in gastric cancer.

\section{Materials and Methods}

\section{Genome-Wide Gene Expression Analysis Using Publicly Available Microarray Data Sets}

We compared POSTN mRNA levels using the following public domain microarray data sets from the Gene Expression Omnibus (GEO, http://www.ncbi.nlm.nih.gov/geo): GSE15460, 25 gastric cancer cell lines and 161 cases of gastric cancer ( 8 cases in T1, 44 cases in T2, 108 cases in T3, and 1 case in T4); GSE7307, 12 cases of normal stomach; and GSE19826, 12 cases of gastric cancer and matched normal tissues in which the clinical TNM stage was available, 3 cases for each stage. Raw data were retrieved and processed using the MAS5 algorithm with target intensity of 500 (Affymetrix, Santa Clara, CA). ${ }^{25}$

Gene Set Enrichment Analysis (GSEA) software ${ }^{26}$ implemented in a Java GSEA desktop application version 2.0 (http://www.broadinstitute.org/gsea/index.jsp) was used to determine whether POSTN has a function correlated with the cell cycle and cell proliferation. Gene sets for use with GSEA were taken from REACTOME (http://www.reactome.org) ${ }^{27}$ and Gene Ontology (GO) (http://www.geneontology.org). ${ }^{28}$ Pearson's correlation coefficient of POSTN per stromal cell [as the ratio of POSTN to vimentin (POSTN/VIM)] and each gene expression level across all samples $>100$ were used to rank genes. Expression levels of probe sets 210809_s_at and 201426_s_at were used as POSTN and VIM mRNA expression, respectively.

\section{Human Tissue Samples}

Human tissue materials (32 non-neoplastic gastric mucosae, 87 intestinal-type gastric cancers, and 50 diffuse-type gastric cancers) were obtained during surgery and retrieved from the archives of the University of Tokyo Hospital during 2005 to 2006. This study was approved by the Ethics Committee of the Graduate School of Medicine of the University of Tokyo (no. 2381).

\section{Cells and Tissue Culture}

Human diffuse-type gastric cancer cell lines OCUM-2MLN and OCUM-12 29 and the mouse fibroblast cell line NIH3T3 expressing POSTN (NIH3T3 $3_{\text {POSTN }}$ ) and its EGFP-expressing control $\left(\mathrm{NIH}_{3} 3_{\mathrm{EGFP}}\right)$ were established as described previously. ${ }^{13}$ OCUM-2MLN, OCUM-12, and the NIH3T3 transfectants were grown in Dulbecco's modified Eagle's medium (Sigma-Aldrich, St. Louis, MO) with $10 \%$ fetal bovine serum (CELLECT FBS, lot no. 5766H; MP Biomedicals, Santa Ana, CA) and $100 \mathrm{U} / \mathrm{mL}$ penicillin-100 $\mu \mathrm{g} / \mathrm{mL}$ streptomycin (Sigma-Aldrich) at $37^{\circ} \mathrm{C}$ in a humid atmosphere saturated with $5 \% \mathrm{CO}_{2}$.

\section{Animals}

C57BL/6 Postn $^{-1-}$ mice (previously established in our laboratory $^{30}$ ) were intercrossed with C57BL/6 Rag2 ${ }^{-1-}$ mice (Taconic Farms, Germantown, NY) to obtain POSTN and RAG-2 double-knockout mice. The method using Rag2 ${ }^{-1-}$ mice had been adopted in a study to survey the function of every type of host-derived matrix metalloproteinase in the cancer microenvironment. ${ }^{31}$ Genotyping procedures for Postn and Rag2 were performed as described previously ${ }^{30}$ and according to the supplier's protocol. Xenograft studies were performed using female BALB/c nude mice, obtained from Charles River Laboratories International (Kanagawa, Japan; Wilmington, MA). Mice were handled under specific-pathogen-free conditions in accordance with the policies of the Animal Ethics Committee of the University of Tokyo (no. 1822T-020).

\section{IHC and Immunofluorescence}

Tissue samples were fixed in $4 \%$ neutral formalin and were embedded in paraffin routinely. The primary antibodies used for the present study included a previously established rabbit polyclonal anti-POSTN,${ }^{5}$ anti- $\alpha$ smooth muscle actin (anti- $\alpha$-SMA) (1:50; 1A4; Dako-Agilent Technologies, Glostrup, Denmark), anti-human Ki-67 (1:200; MIB-1; Dako-Agilent Technologies), and anti-p-p44/42 MAPK 
(1:200; no. 9101; Cell Signaling Technology, Danvers, MA). IHC and immunofluorescence microscopy were performed (sections $5 \mu \mathrm{m}$ thick) as described previously. ${ }^{13}$ For semiquantifying POSTN expression, we scored four groups according to prevalence: score $0,<10 \%$; score $1,10 \%$ to $49 \%$; score $2,50 \%$ to $80 \%$; and score $3,>80 \%$. We regarded scores 2 and 3 as significant and positive.

\section{In Situ Hybridization for POSTN mRNA}

Antisense and sense complementary (c)RNA probes were prepared by in vitro transcription of EcoRI-XbaI fragment of human and mouse POSTN cDNA using a DIG labeling mix (Roche Applied Science, Indianapolis, IN) as described previously. ${ }^{32}$ Nonradioactive mRNA in situ hybridization was performed manually on formalin-fixed, paraffinembedded sections ( $5 \mu \mathrm{m}$ thick) as described previously. ${ }^{13}$

\section{Three-Dimensional Coculture with Cancer Cells and Fibroblasts}

OCUM-2MLN and either of the NIH3T3 transfectants (NIH3T3 $3_{\text {POSTN }}$ or NIH3T3 $3_{\text {EGFP), each at a final concentra- }}$ tion of $1 \times 10^{6} / \mathrm{mL}$, were suspended in $1 \mathrm{~mL}$ of the mixture of type I collagen gel. Three-dimensional coculturing was then performed for 2 weeks, as described previously. ${ }^{13}$ Subsequently, $10 \%$ phosphate-buffered and formalinfixed, paraffin-embedded sections were studied with $\mathrm{H} \& \mathrm{E}$ staining. Microphotographs of $>50$ foci were taken at random locations and cancer cells per high-power field were counted.

\section{Proliferation Assay}

Proliferation assay was performed using a cell-counting kit (CCK-8; Dojindo Molecular Technologies, Kumamoto, Japan) as described in the technical manual. The final concentration was supplemented with $0.1 \%$ bovine serum albumin and either recombinant human POSTN (250 ng/ $\mathrm{mL}$, BioVendor, Heidelberg, Germany) dissolved in PBS or vehicle alone.

\section{Phosphorylated MAP Kinase Protein Array}

Phosphorylated MAP kinase protein array analysis was performed using a human p-MAPK array kit (Proteome Profiler antibody array; R\&D Systems, Minneapolis, MN) according to the manufacturer's instructions. Samples of cell lysates were obtained after 24 hours incubation in a noserum condition, supplemented with $1 \mu \mathrm{g} / \mathrm{mL}$ of recombinant human POSTN (BioVendor) or equal amounts of PBS. p-MAPK levels were detected using chemiluminescence. The signal intensity was quantified using an LAS-3000 imaging system (Fujifilm, Tokyo, Japan) and Multi Gauge software version 2.2 (Fujifilm).

\section{Western Blotting}

For detection of ERK phosphorylation by POSTN, cells were cultured overnight in a no-serum condition after 1 hour of incubation supplemented with $250 \mathrm{ng} / \mathrm{mL}$ of recombinant human POSTN (BioVendor) or equal amounts of PBS. Cell lysate samples were prepared in radioimmunoprecipitation assay buffer separated on $8 \%$ polyacrylamide gels. They were electroblotted onto a polyvinylidene difluoride membrane. After blocking, the membranes were incubated for 1 hour at room temperature with an anti-ERK (1:1000; sc-94; Santa Cruz Biotechnology) or an anti-p-p44/42 MAPK (1:1000; no. 9101; Cell Signaling Technology). The membranes were washed again and incubated for 1 hour with secondary antibodies. The antigen was then detected using enhanced chemiluminescence Western blot detection reagents (GE Healthcare, Little Chalfont, UK) according to the manufacturer's instructions.

Coinoculation of OCUM-2MLN or OCUM-12 Diffuse-Type Gastric Cancer Cells with NIH3T3 $3_{\text {POSTN }}$ Cells in Vivo

OCUM-2MLN or OCUM-12 $\left(5 \times 10^{6}\right.$ cells $)$ and NIH3T3 $3_{\text {POSTN }}$ or NIH3T3 $3_{\text {EGFP }}\left(1 \times 10^{6}\right.$ cells $)$ were suspended in $50 \mu \mathrm{L}$ of PBS and were coinjected subcutaneously in the flanks (left flank with NIH3T3 $3_{\text {POSTN }}$; right flank with NIH3T3 $3_{\text {EGFP) }}$ of nude mice. Tumor volumes were calculated using the following formula: volume $V=\left(W^{2} \times L\right) / 2$, where $W$ is the short diameter and $L$ is the long diameter. Histological features of the xenografts were examined with $\mathrm{H} \& \mathrm{E}$ staining. H\&E sections were scanned using a Nanozoomer 2.0HT system (Hamamatsu Photonics, Hamamatsu, Japan) and the tumor area was analyzed using NDP.view viewer software version 1.1.27 (Hamamatsu Photonics).

\section{Orthotopic Inoculation Model of Diffuse-Type Gastric Cancer Cell Line}

A total of $5 \times 10^{6}$ cells suspended in $50 \mu \mathrm{L}$ of PBS were inoculated subserosally into the gastric walls of mice, as described previously. ${ }^{29}$ For the present study, we used Postn ${ }^{-1-}$ Rag2 $^{-/-}$mice $(n=6)$ and Postn ${ }^{+/+}$Rag2 $^{-1-}$ mice $(n=7)$, aged 4 to 5 weeks. At 5 weeks after inoculation, the mice were sacrificed for subsequent evaluation procedures.

\section{Statistical Analysis}

For analysis of publicly available microarray data sets, the data were evaluated using Wilcoxon signed-rank test for statistical comparisons. The trend test was performed with a Jonckheere-Terpstra test. For the distribution of POSTN expression in IHC, a Cochrane-Armitage trend test was applied. These statistical tests were performed using $\mathrm{R}$ software version 2.11 .0 (http://www.r-project.org). In vitro and in vivo growth data were evaluated with two-way analysis of variance using GraphPad Prism software 
version 4 (GraphPad Software, San Diego, CA). All other numerical results are expressed as means \pm SEM. Data were evaluated using $U$-tests for statistical comparisons using StatView software version 4 (SAS Institute, Cary, NC). $P<0.05$ was considered significant for all statistical tests.

\section{Results}

\section{Microarray Data Set Analysis of POSTN mRNA Expression in Gastric Cancer}

To study whether POSTN expression is up-regulated in gastric cancer, we first analyzed POSTN mRNA levels in normal gastric tissue, gastric cancer tissue, and gastric cancer cell lines from publicly available microarray data sets (GSE15460 and GSE7307). POSTN expression was found in both normal and neoplastic tissues, without any marked differences, although all gastric cancer cell lines (excepting only YCC11) expressed negligible POSTN (Figure 1A). In a closer comparison of POSTN mRNA expression levels between cancer and matched normal stomach samples, we analyzed another data set including an annotation for the clinical stage (GSE19826). It is particularly interesting that no difference between cancer and normal tissue samples was found for stage I gastric cancer $(P=0.98$, Wilcoxon signedrank test; $n=3$ ), although cancer tissue samples showed significantly higher POSTN expression than each corresponding background normal tissue for stage II, III, and IV gastric cancer $(P=0.049$, Wilcoxon signed-rank test; $n=9)$ (Figure 1B)

We further analyzed the correlation between POSTN mRNA level and tumor progression using the GSE15460 data set. The trend test results showed that the POSTN mRNA expression in tumor samples was proportionally greater at the higher $\mathrm{T}$ stages $(P=0.0033$, Jonckheere-Terpstra test $)$ (Figure 1C).

To correlate the stromal amount and VIM expression, we analyzed the data set GSE8218, comprising 136 cases of prostate cancer for which the stromal percentage was available for each tumor sample (Supplemental Figure S1). Raw data were retrieved and processed using the MAS5 algorithm (Affymetrix). Pearson correlation coefficients indicated correlation between VIM mRNA expression and the amount of stroma in prostate cancer $(R=0.525$,
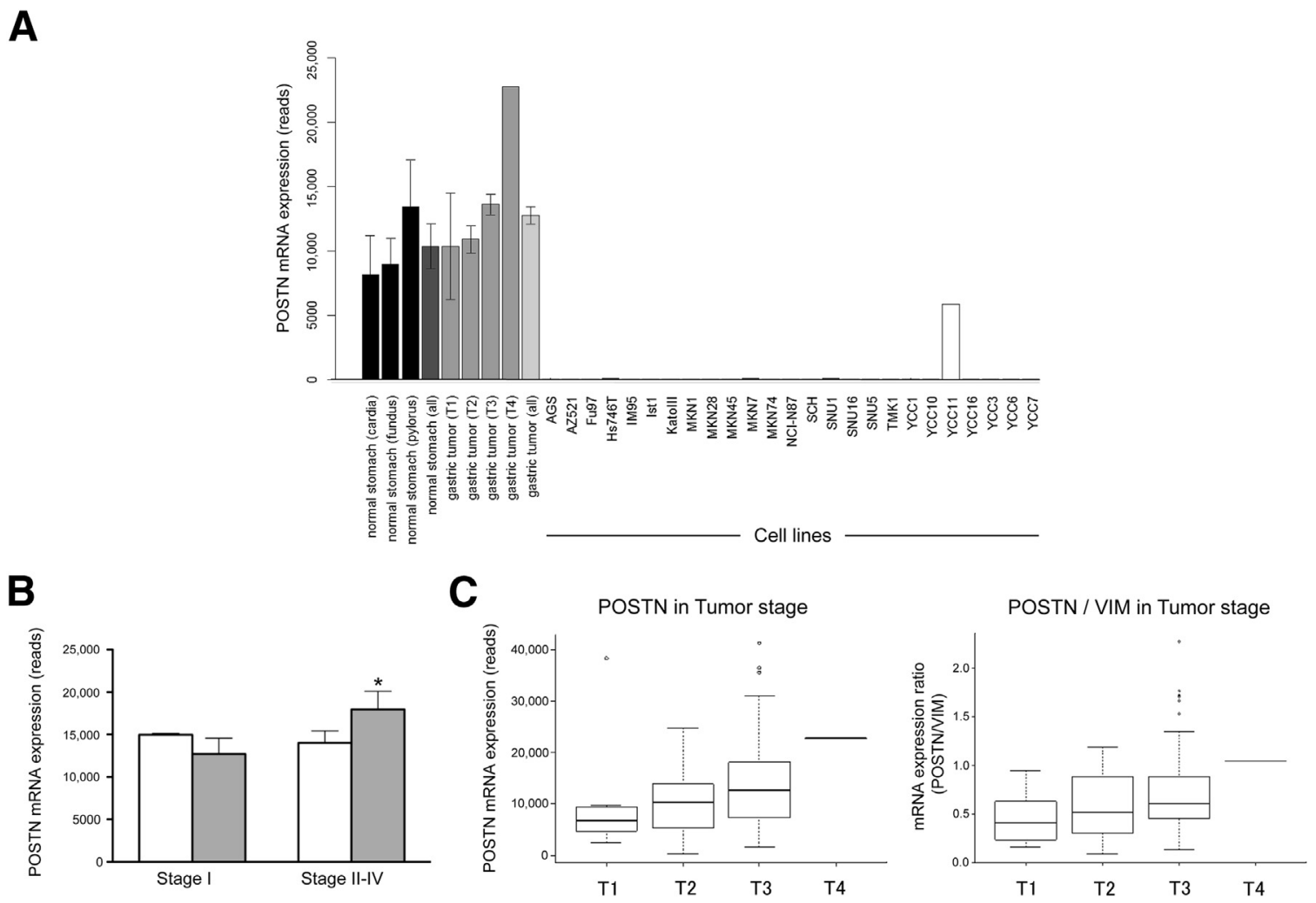

Figure 1 POSTN mRNA expression in normal stomach and gastric cancer from publicly available microarray data sets. A: Expression of POSTN mRNA in normal gastric tissue $(n=12)$, gastric cancer tissue $(n=161)$, and gastric cancer cell lines $(n=25)$. B: Comparison of POSTN mRNA expression levels between cancer and matched normal stomach samples. No difference was found between cancer (gray bars) and normal tissue (white bars) samples in stage I gastric cancer $(P=0.98)$, but for stage II, III, and IV gastric cancer tissue samples showed significantly higher POSTN expression than the corresponding background normal tissues. $P=0.049$. C: Correlation between POSTN expression and tumor progression. POSTN mRNA expression in tumor samples was greater at the higher T stages $(P=0.00339)$. The POSTN/VIM mRNA expression ratio was also associated significantly with T stage $(P=0.0077)$. Boxplots indicate the median and first and third quartiles; whiskers indicate the 10th and 90th percentiles. Outlier values ( $>1.5$ box-lengths from the 3 rd quartile) are indicated by symbols (circles). ${ }^{*} P<0.05$. 
$\left.P=5.35 \times 10^{-11}\right)($ Supplemental Figure S1). No correlation was found between keratin 18 mRNA expression and the stromal amount (data not shown).

To standardize the number of stromal cells, we next performed a trend test against POSTN/VIM mRNA expression ratio. The POSTN/VIM mRNA expression ratio in tumors was also associated significantly with the $\mathrm{T}$ stage $(P=0.0077$, Jonckheere-Terpstra test) (Figure 1C).

\section{POSTN Expression in Gastric Mucosa and Gastric Cancer}

We extensively investigated POSTN protein expression in both non-neoplastic and neoplastic gastric tissues. Two distinctive immunostaining patterns, indicative of periglandular and stromal POSTN deposition, were noted in the ECM of normal gastric mucosa. Periglandular-type staining showed linear POSTN immunoreactivity abutting the gastric foveolus and surrounding the proper gastric glands (Figure 2, A-C). Stromal staining, however, was indicative of intense POSTN deposition in the ECM of reactive gastric mucosa, in
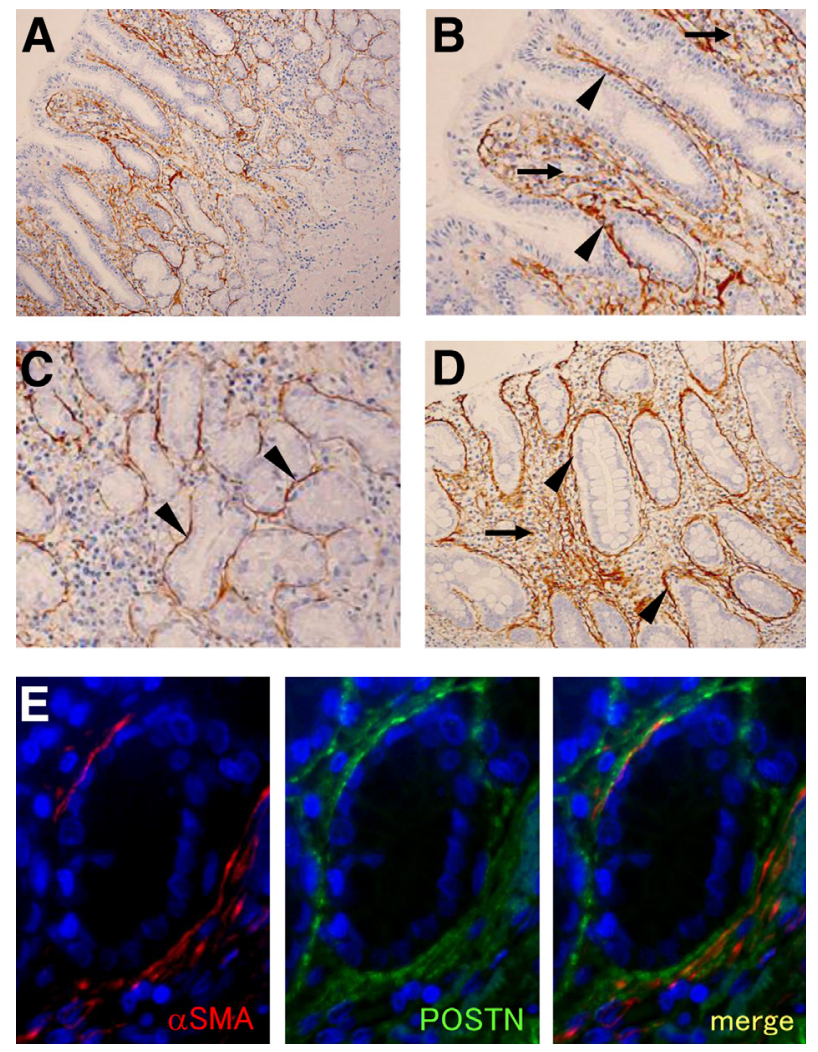

Figure 2 POSTN expression in non-neoplastic gastric mucosa. A: Immunostaining of normal gastric mucosa, showing POSTN expression in the lamina propria mucosae, but not in epithelial cells. B-D: High-power magnification of the foveolar epithelial region (B), the proper gastric gland region (C), and the intestinal metaplasia area (D) reveals circumscribed POSTN immunostaining (arrowheads) and a fine network of immunoreactive POSTN (arrows). Note prominent periglandular POSTN immunoreactivity in the intestinal metaplasia area. E: Double immunofluorescence staining for $\alpha$-SMA and POSTN. The merged image shows focal colocalization immunoreactivity of $\alpha$-SMA and POSTN surrounding the gland. Original magnification: $\times 200($ A-D); $\times 400($ E) . which there is an inflammatory cell infiltrate and an increase in vascularity, in addition to more pronounced periglandular immunoreactive POSTN in the intestinal metaplasia area (Figure 2D). The stromal staining pattern was barely visible in the normal lamina propria mucosae. Immunofluorescent double staining for POSTN and $\alpha$-SMA showed a focal close approximation of $\alpha-\mathrm{SMA}^{+}$cells to POSTN immunoreactivity, which encircled normal gastric glands (Figure 2E). No specific staining of epithelial cells or other mesenchymal cell types was noted, with the exception of occasional POSTN deposition in the vascular wall. In the submucosal and muscular layer, POSTN expression was focally detected in perivascular cells of capillaries (data not shown).

Next, we examined POSTN expression in gastric adenocarcinomas according to the two histological subtypes, the intestinal type $(n=87)$ and the diffuse type $(n=50){ }^{23}$ Periglandular POSTN staining was found in all of the nonneoplastic tissues $(n=14)$, although it was dramatically lower in carcinoma of the intestinal subtype at Tis, in 19\% (10/ 52) of cases, which did not involve the basement membrane (Figure 3, A-C, and Supplemental Table S1). Furthermore, periglandular POSTN staining was observed in only $8 \%(1 / 13)$ of cases of the invasive intestinal-type adenocarcinomas at $\mathrm{T} 1$, which involved the lamina muscularis mucosae and which extended into the submucosa (Figure 3C). Periglandular POSTN expression tended to decrease with progressing stage $\left(P=7.62 \times 10^{-8}\right)$. Invasive intestinal-type adenocarcinomas in stages T2 to T4 showed prominent stromal POSTN deposition, rather than periglandular staining (Figure 3D), in contrast to noninvasive intestinal-type cancers. The immunoreactive POSTN was fibrillar and was confined at the invasive front of invasive tumor nests. However, all diffuse-type adenocarcinomas, especially the linitis plastica type, showed prominent stromal-type POSTN staining in the lamina propria mucosae and stroma of the deeper layers at all $\mathrm{T}$ stages (Figure 3, E and F). Cochran-Armitage trend testing revealed that stromal POSTN expression increased with progressing stage in both intestinal-type $\left(P=8.12 \times 10^{-5}\right)$ and diffusetype $\left(P=7.54 \times 10^{-4}\right)$ gastric cancer. No staining of carcinoma cells for POSTN was noted at any point during the IHC investigation.

\section{Stromal Myofibroblasts Express POSTN in Gastric Cancer}

In gastric cancer tissue, fibroblastic stromal cells, which lie in a dense collagenous matrix, show strong stromal immunoreactivity for POSTN (Figure 3, G and H). Immunofluorescent double-staining for $\alpha$-SMA and POSTN in advanced invasive cancer showed that $\alpha$-SMA ${ }^{+}$fibroblasts were embedded in a cancer stroma, which contained abundant immunoreactive POSTN. Focal colocalization of POSTN and $\alpha$-SMA signals occurred (Figure 3G). Positive signal for POSTN mRNA was noted in fibroblastic stromal cells, but not in carcinoma cells (Figure 3I). These findings indicate that POSTN is expressed and secreted by stromal myofibroblasts in gastric cancer. 
Proliferative Function of POSTN for Gastric Cancer Cell via ERK Phosphorylation

We examined a possible correlation between POSTN transcripts and other genes using public domain microarray data sets from the GEO (http://www.ncbi.nlm.nih.gov/geo; accession no. GSE15460) with GSEA software. ${ }^{26}$ Among the gene groups associated with the POSTN/VIM-high mRNA expression ratio, the gene groups that regulate cell cycle (REACTOME and GO gene sets) and cell proliferation (GO gene sets) were highly ranked $(P<0.0002)$ (Figure 4A and Supplemental Tables S2 and S3). These results suggest that high POSTN expression per stromal cell is associated with the cell cycle and cell proliferation in gastric cancer.

The growth effect of POSTN for tumor cells was evaluated using OCUM-2MLN and OCUM-12 diffuse-type gastric cancer cell lines. Both OCUM-2MLN and OCUM12 cells showed a significant increase in cell number with supplementation of a recombinant human POSTN (Figure 4B). For the assessment of cancer-stromal interaction in vitro, we performed three-dimensional coculture in type I collagen gel together with OCUM-2MLN cells and previously established POSTN-expressing NIH3T3 transfectants $\left(\mathrm{NIH}_{3} \mathrm{~T}_{\text {POSTN }}\right){ }^{13}$ The cancer cells were significantly more numerous in NIH3T3 $3_{\text {POSTN }}$ coculture than in the coculture with control (Figure 4C).

To investigate the underlying mechanism of the capacity of POSTN to promote cell proliferation, we screened phosphorylated MAP kinase proteins expressed in OCUM2MLN cells. Incubation of recombinant POSTN caused phosphorylation of ERK1 and ERK2, at levels approximately twofold and threefold greater, respectively, than
A

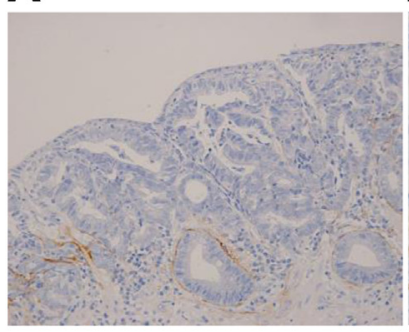

D

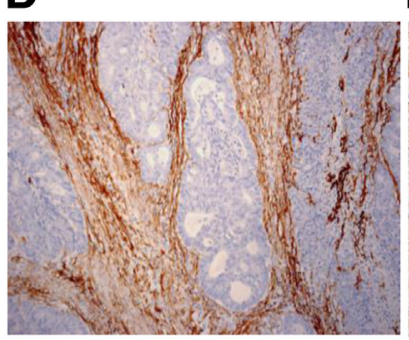

B

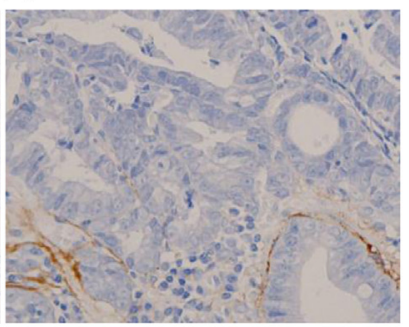

E

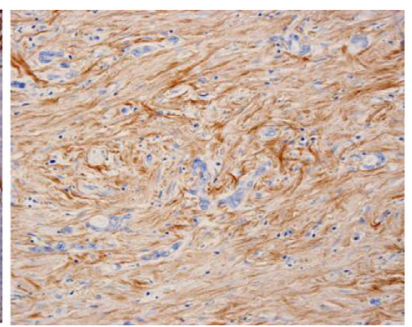

C

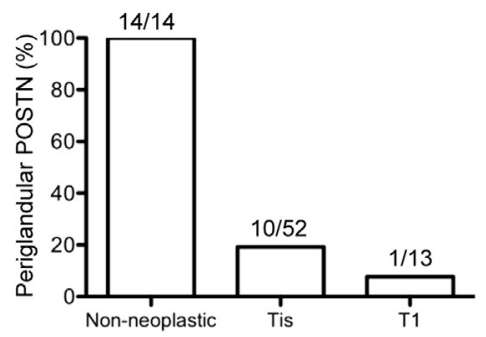

$\mathbf{F}$

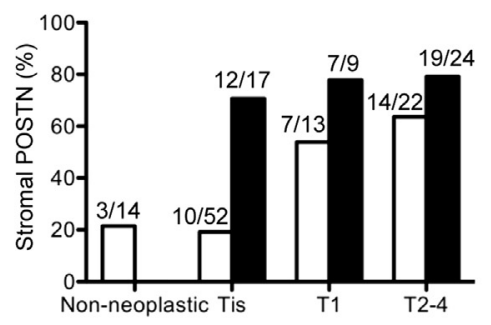

G

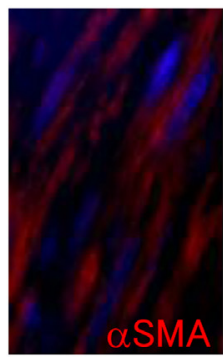

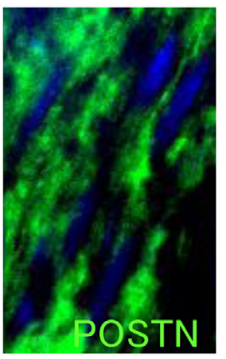

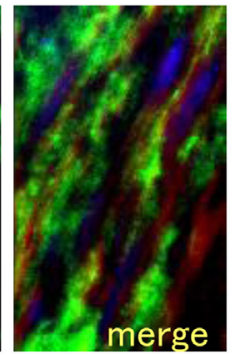

H

I

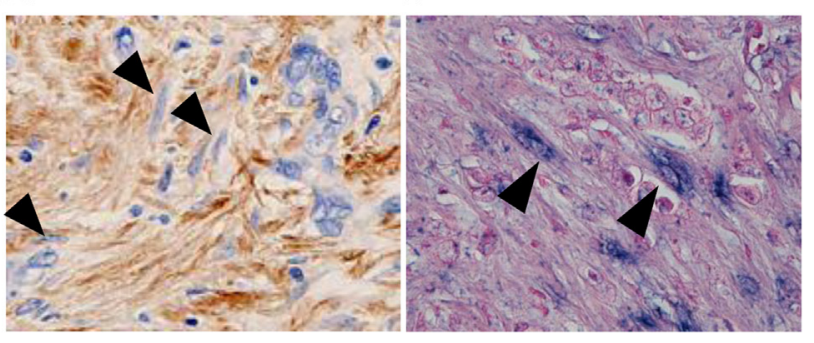

Figure 3 POSTN expression in gastric cancer. A and B: Immunostaining of intestinal-type adenocarcinoma with no extension into the lamina propria mucosae. Diminished periglandular POSTN immunoreactivity is evident in the tumor glands. C: Semiquantitative evaluation of periglandular immunostaining for POSTN in normal stomach and Tis/T1 intestinal-type gastric cancers. IHC scores of 2 and 3 were regarded as significant and positive. Periglandular POSTN staining was lost with stage progression $\left(P=7.62 \times 10^{-8}\right)$. D: Stromal POSTN expression in invasive intestinal-type adenocarcinoma. E: Stromal POSTN expression in diffuse-type adenocarcinoma. F: Semiquantitative evaluation of stromal POSTN. IHC scores of 2 and 3 were regarded as significant and positive. Stromal POSTN expression increased with stage progression in both intestinal-type (white bars; $P=8.12 \times 10^{-5}$ ) and diffuse-type (black bars; $P=7.54 \times 10^{-4}$ ) gastric cancer. G: Immunofluorescence double staining for $\alpha$-SMA and POSTN in invasive diffuse-type gastric cancer. H: Stromal POSTN expression in diffuse-type gastric cancer at high magnification. Fibroblastic cells are visible in the cancer stroma (arrowheads). I: POSTN mRNA expression in diffuse-type gastric cancer (in situ hybridization). Positive signals were noted in the fibroblastic cells in cancer stroma (arrowheads), although no signal was observed in cancer cells. Original magnification: $\times 400$. 
A

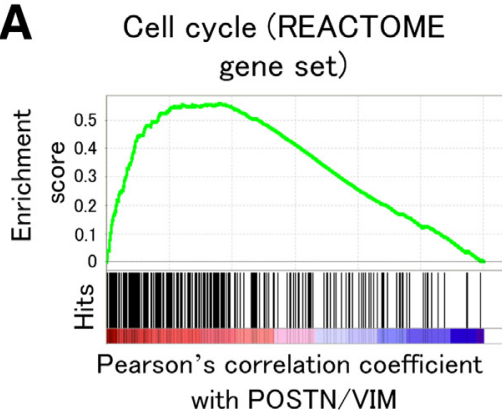

B

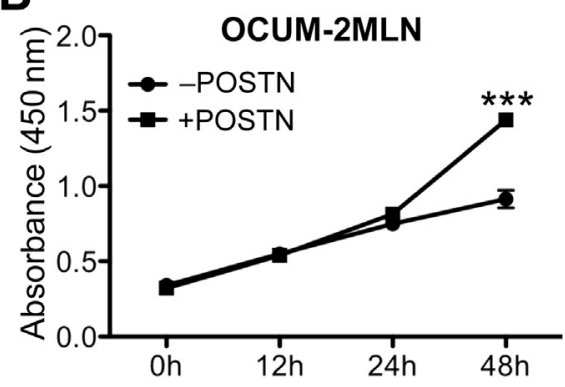

C

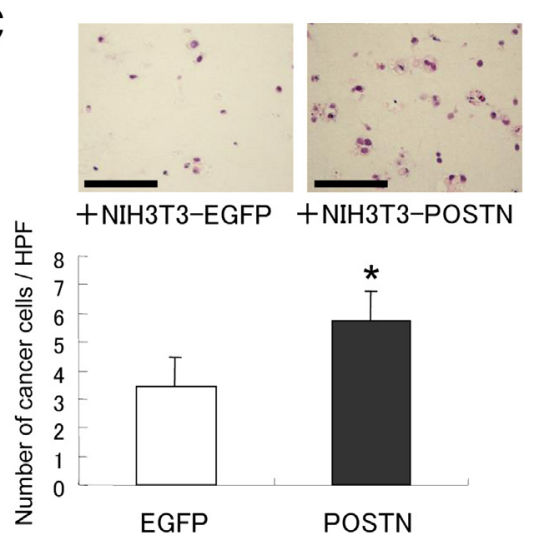

Cell proliferation (GO gene set)
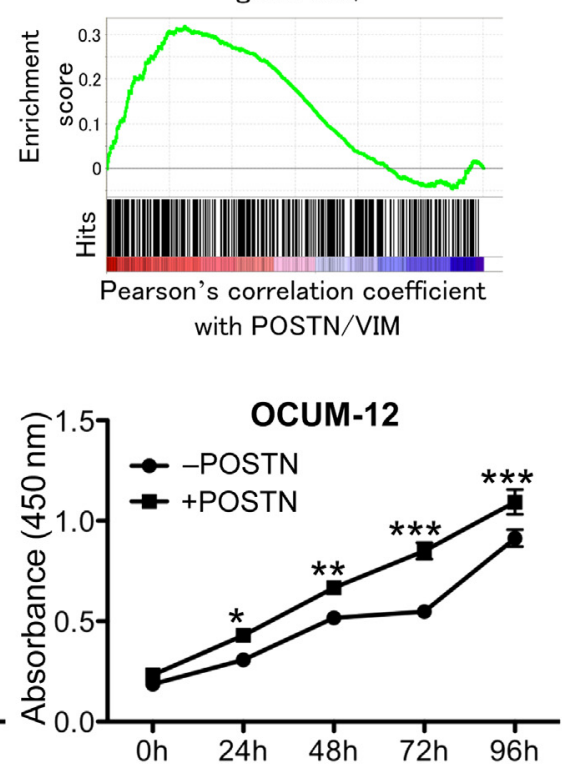

D
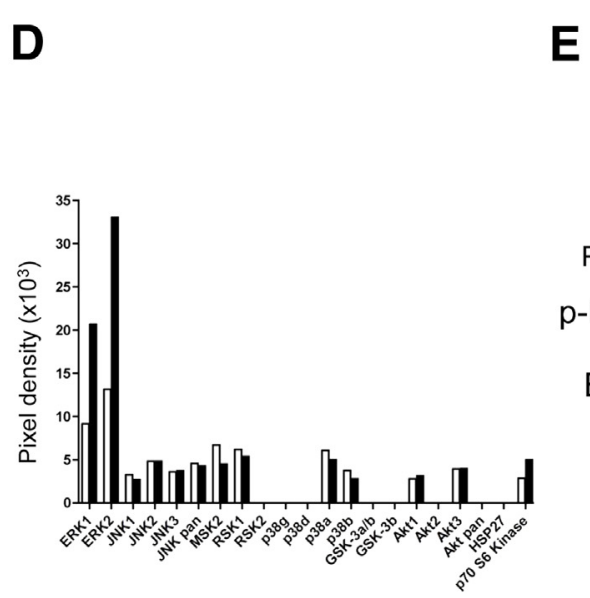

Figure 4 Effect of POSTN in a gastric cancer cell line in vitro. A: Analysis with GSEA software ${ }^{26}$ demonstrates significant enrichment of cellcycle genes $(P<0.0002)$ and cell-proliferation genes $(P<0.0002)$ among genes showing high Pearson's correlation with the POSTN/VIM mRNA expression ratio. Black vertical lines indicate gene hits. Pearson's correlation coefficient is indicated from high to low (left to right). B: Proliferation assay of OCUM-2MLN or OCUM-12 with or without POSTN $(250 \mathrm{ng} / \mathrm{mL})$. C: Threedimensional coculture assay of OCUM-2MLN with NIH3T3 transfectants. The number of cancer cells per high-power field is higher in the condition with POSTN-expressing NIH3T3 transfectants than with the EGFP-expressing control. D: Human p-MAPK array assay of OCUM-2MLN cells with (black bars) or without (white bars) POSTN $(1 \mu \mathrm{g} / \mathrm{mL})$, for phosphorylated kinases. E: Western blot analysis of OCUM-2MLN or OCUM-12 cells with or without POSTN $(250 \mathrm{ng} / \mathrm{mL}$ for 1 hour) for ERK and p-ERK. Data are expressed as means \pm SEM. ${ }^{*} P<0.05,{ }^{* *} P<0.01$, and ${ }^{* * *} P<0.001$. Scale bar $=100 \mu \mathrm{m}$.

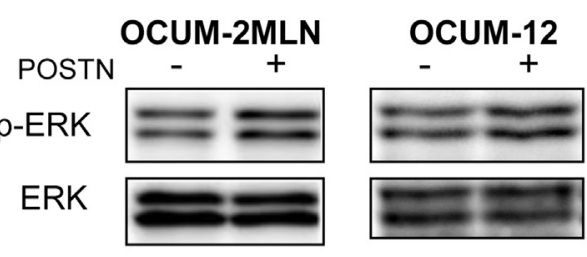

those of controls (Figure 4D). No phosphorylation of the other MAP kinase proteins was detected. Induction of $\mathrm{p}$ ERK by POSTN in OCUM-2MLN and OCUM-12 cells was confirmed by Western blotting (Figure 4E).

\section{Coinoculation of OCUM-2MLN or OCUM-12 Diffuse-Type} Gastric Cancer Cells Line with NIH3T3 $3_{\text {POSTN }}$ Cells in Vivo

To examine the role of stromal POSTN in gastric tumor growth in vivo, OCUM-2MLN or OCUM-12 gastric cancer cells were coinoculated with POSTN-expressing mouse fibroblast NIH3T3 cells. OCUM-2MLN cells coinoculated with NIH3T3 $3_{\text {EGFP }}$ or NIH3T3 ${ }_{\text {POSTN }}$ (OCUM$2 \mathrm{MLN}-\mathrm{NIH} 3 \mathrm{~T}_{\text {EGFP }}$ and OCUM-2MLN-NIH3T3 $\left.3_{\text {POSTN }}\right)$ caused tumor formation in $100 \%$ of mice (6/6) in both groups. Tumors in mice injected with OCUM-12-NIH3T3 $3_{\text {POSTN }}$ cells grew faster and were larger at the end of the experiment than tumors injected with OCUM-12-NIH3T3 $3_{\text {EGFP }}$ cells (Figure 5, A and B). However, one of the six mice injected with OCUM-12-NIH3T3 $3_{\text {EGFP }}$ did not form a tumor (Figure 5B), whereas all six of the mice injected with OCUM12-NIH3T3 $3_{\text {POSTN }}$ formed tumors. OCUM-2MLN cells coinoculated with NIH3T3 $3_{\text {POSTN }}$ also showed a tendency to form larger tumors than the control, but the difference was not significant (Figure 5A). Intriguingly, OCUM-2MLN cells formed well-vascularized tumors, whereas OCUM-12 cells showed only moderate change (Figure $5 \mathrm{~B}$ ). H\&E staining revealed that coinoculation with $\mathrm{NIH}_{3} 3_{\text {POSTN }}$ led to larger tumors, with central necrosis, in the OCUM-2MLN group, compared with the OCUM-12 group (Figure 5C). Analysis of the invasive tumor lesion area, with the necrotic area excluded from the total tumor area, revealed that coinoculation with NIH3T3 $3_{\text {POSTN }}$ led to larger tumor lesion area, compared with coinoculation with NIH3T3 EGFP $_{\text {(Figure 5D). OCUM- }}$ 12-NIH3T3 $3_{\text {POSTN }}$ cells led to macroscopically larger tumors (Figure 5, A and B), and also had the same tendency to form a larger invasive lesion area as OCUM-2MLN-NIH3T3 $3_{\text {POSTN }}$ cells $(P=0.05)$ (Figure 5, C and D). 


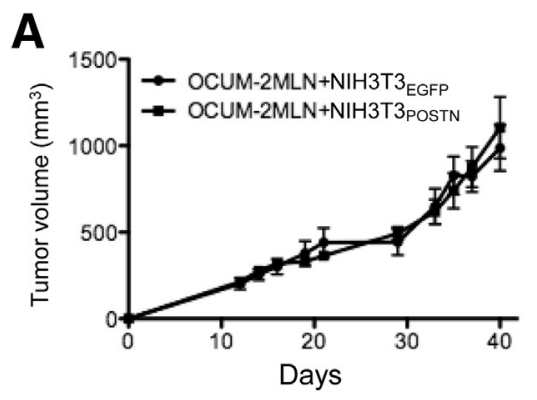

B

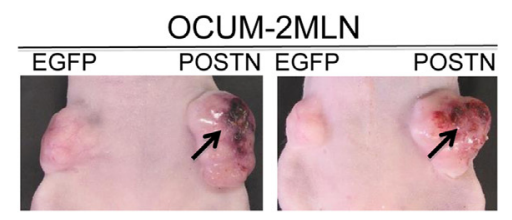

C
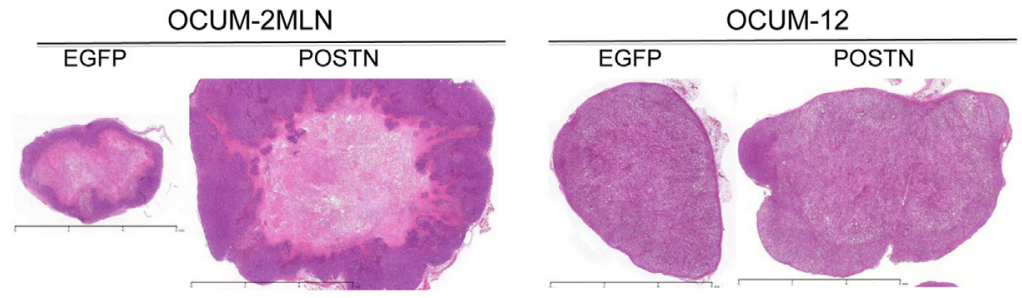

Figure 5 Coinoculation of gastric cancer cell lines with fibroblast-expressing POSTN. A: A diffusetype gastric cancer cell line, OCUM-2MLN or OCUM12, with NIH3T3 $3_{\text {EGFP }}$ or NIH3T3 ${ }_{\text {POSTN }}$, was injected subcutaneously into nude mice. B: Final tumor size. Vascularized areas are indicated by arrows. C: Histological appearance of the maximum cut surface of inoculated tumor in nude mice. D: Invasive lesion areas were measured, with the necrotic area excluded, and compared using NDP.view software. Scale differs between OCUM-2MLN and OCUM-12. ${ }^{*} P \leq 0.05,{ }^{* *} P<0.01$. Scale bar $=6 \mathrm{~mm}$.
D

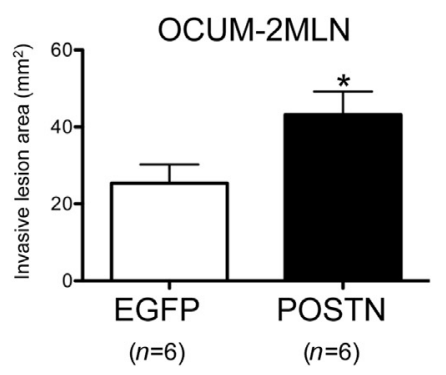

OCUM-12

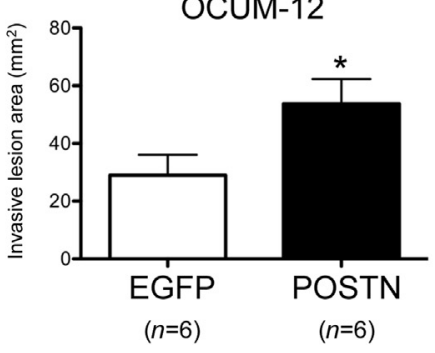

Orthotopic Inoculation Model of Diffuse-Type Gastric Cancer in Postn ${ }^{-/-}$and Postn ${ }^{+/+}$Rag2 Knockout Mice

To further examine the function of host-derived POSTN in cancer stroma, we inoculated OCUM-2MLN cells into the gastric wall of Postn ${ }^{-1}$ Rag2 $^{-/-}$double-knockout mice. The OCUM-2MLN cells formed invasive tumors in both Postn $^{-/-}$and wild-type (Postn ${ }^{+/+}$) Rag2 knockout mice (Figure 6A). We analyzed the tumor area inside the gastric wall, excluding the necrotic area from the total tumor area (Figure 6A). The tumor area in Postn ${ }^{-1-}$ mice was significantly smaller than that in Postn ${ }^{+/+}$mice (Figure 6B). Stromal immunostaining for POSTN was observed only in Posth $^{+/+}$mice (Figure 6C). In situ hybridization showed positive signals for POSTN mRNA in stromal fibroblasts in Postn $^{+/+}$mice, but not in Posth ${ }^{-/-}$mice (Figure 6C). No expression of POSTN protein or mRNA was noted in the inoculated tumor cells. Moreover, a significantly lower fraction of Ki-67 $7^{+}$cancer cells was found in Postn ${ }^{-/-}$mice than in Posth $^{+/+}$mice (Figure 6, C and D), and immunostaining for $\mathrm{p}$-ERK revealed a significantly lower number of p-ERK ${ }^{+}$cancer cells in Postn ${ }^{-1-}$ mice than in Posth $^{+/+}$mice (Figure 6, C and E). These data suggest that host-derived POSTN was produced by CAFs and promoted cancer cell proliferation via activation of ERK signaling cascades.

\section{Discussion}

Histological features distinguish the intestinal and diffuse types of gastric carcinoma,. ${ }^{23}$ The diffuse type comprises poorly cohesive or signet-ring cell carcinoma lying in an abundant desmoplastic stroma. In the present study, stromal cells in gastric cancer produced POSTN. Whether POSTN in the cancer stroma is secreted by the cancer cells or CAFs has been equivocal in certain cancer types. ${ }^{13,15,16,33,34}$ Analysis of publicly available microarray data sets showed that no gastric cancer cell lines expressed POSTN mRNA except YCC11; these cells harbor a unique, nonbenign 


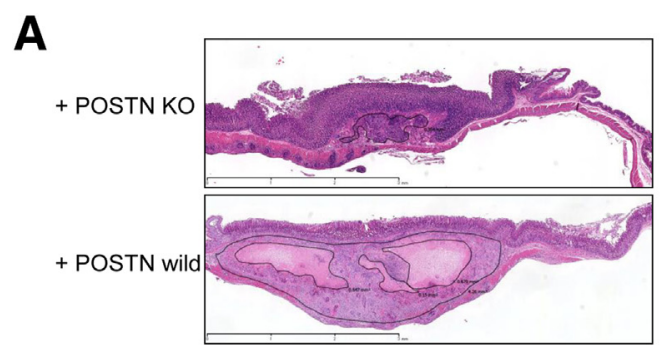

C

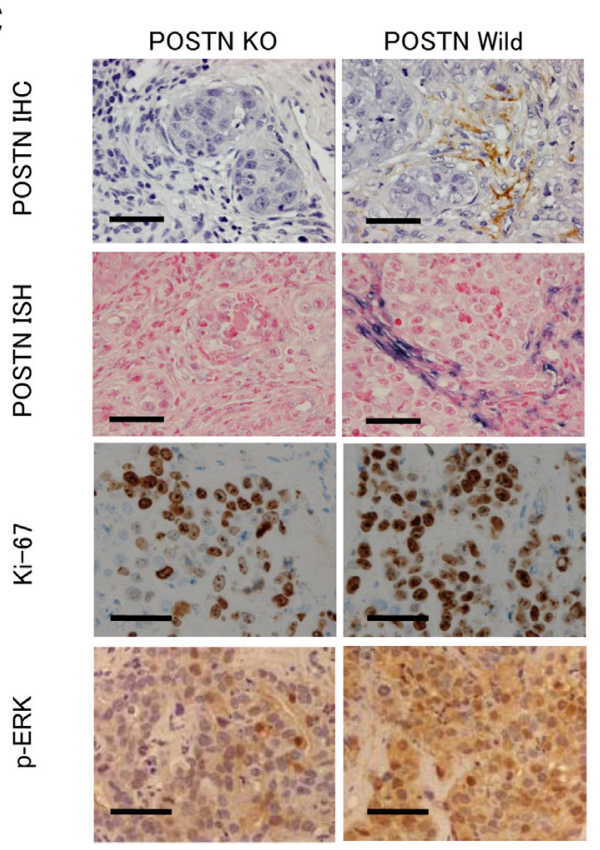

B

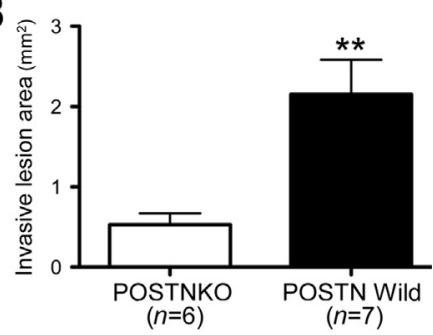

D

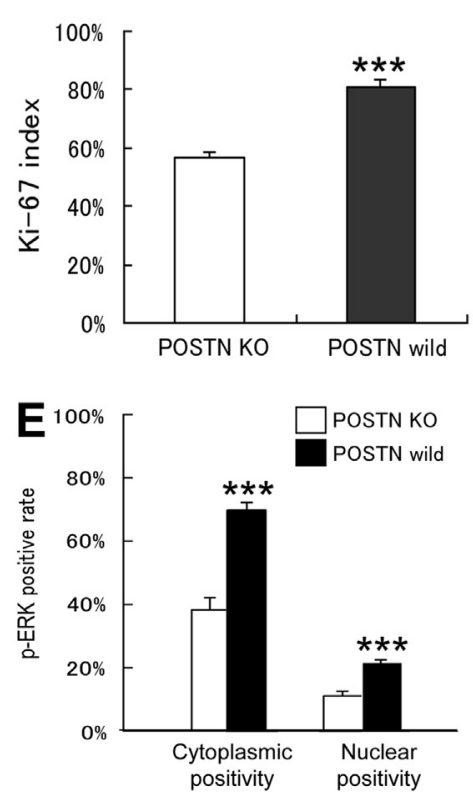

Figure 6 Orthotopic inoculation model of diffuse-type gastric cancer in immunodeficient Postn $^{-/-}$or Postn ${ }^{+/+}$mice. A: Histological appearance of the maximum cut surface of inoculated tumor in Postn ${ }^{-1-}$ mice (POSTN KO) and wild-type Postn ${ }^{+/+}$mice (POSTN wild). Invasive lesion area, with the necrotic area excluded from the total tumor area, is outlined in black. B: Areas of respective invasive lesions inside the gastric wall were measured using NDP.view software. C: IHC for POSTN, in situ hybridization (ISH) for POSTN mRNA, and IHC for Ki-67 and p-ERK. D and E: Quantitative analysis of $\mathrm{Ki}-67^{+}(\mathrm{D})$ and $\mathrm{p}$-ERK ${ }^{+}$ (E) tumor cells. ${ }^{* *} P<0.01,{ }^{* * *} P<0.001$. Scale bars: $3 \mathrm{~mm}$ (A); $50 \mu \mathrm{m}$ (C). single-nucleotide variant in RPS6KA6, which might be related to POSTN expression via activation of CREB, a known inducer of POSTN. ${ }^{35}$ It is particularly interesting that POSTN mRNA expression was correlated with that of VIM but not with that of keratin 18 (data not shown), suggesting that POSTN is produced by nonepithelial cells rather than by neoplastic cells in gastric cancer. Significant correlation was found between the POSTN mRNA expression level and clinical and biological behavior. When the POSTN-expressing level was standardized per stromal cell using the VIM expression level (POSTN/VIM), gene groups regulating the cell cycle and cell proliferation were ranked highly by an association of the POSTN/VIM mRNA expression ratio and other genes using GSEA software. ${ }^{26}$ The strategy in bioinformatics, standardizing data for each cell type, is therefore crucial in mining data sets in cancer studies, especially in the context of cancer-stromal interaction, in which mixed cell populations are involved. Our results suggest that POSTN plays a role in cell proliferation in the gastric cancer microenvironment.

Interaction between epithelial cells and ECM in the microenvironment is necessary for the maintenance of normal glandular structures. This association is recognized more specifically as a stem cell and its niche; POSTN is an ECM molecule comprising the niche. ${ }^{1}$ IHC investigation showed that POSTN immunoreactivity frequently circumscribed the foveolar epithelium and the gastric glands in normal gastric mucosa. In addition, stromal and more pronounced periglandular POSTN staining was noted in gastric mucosa, indicative of intestinal metaplasia under a chronic inflammatory condition. These findings resemble those of POSTN expression in other inflammatory diseases, such as asthma and atopic dermatitis. ${ }^{36,37}$ In these allergic conditions, recruited Th2 cells (in asthma) and epithelial cells (in atopic dermatitis) respectively release IL-4 and IL- $13^{38}$ and growth factors such as TGF- $\beta 1 .^{3}$ These factors induce POSTN overexpression by activated myofibroblasts, which in the airway disease increases goblet cells. Our IHC findings thus strongly suggest that the alteration of POSTN expression reflects the disruption of homeostasis in the lamina propria mucosae niche.

The mucosal microenvironment exhibits minimal morphological change in carcinoma in situ. ${ }^{39}$ In stomach, the histological definition of carcinoma in situ is still equivocated by histopathologists, ${ }^{40}$ but it seems readily apparent that atypical tumor glands retain the basement membrane, and that the lamina muscularis mucosae is intact in Tis and T1 intestinal-type gastric adenocarcinomas. In these early-form or noninvasive cancers, periglandular POSTN staining was lost during progression, and the stromal overexpression of 
POSTN that is found in advanced cancer was not observed. The neoplastic glands were irregular, and some periglandular POSTN stainings were lost, but the basement membrane remained apparently intact in a reactive stroma, in which there was mildly increased fibroblast cellularity. Our findings resemble those reported for $C d x 2$ transgenic mouse gastric carcinomas,${ }^{41}$ as well as those for human colorectal carcinomas in which immunoreactive pericryptal POSTN disappeared along the colorectal adenoma-carcinoma sequence. ${ }^{13}$ When epithelial-periglandular fibroblast interaction is disrupted in the local mucosal niche, it is possible that periglandular POSTN staining is eventually lost during progression of the early form of intestinal-type gastric cancer.

In fact, CAFs (fibroblasts in the tumor stroma) acquire a modified phenotype, which is seen in myofibroblasts in the wound healing process. ${ }^{34}$ The CAFs, which interact with cancer cells to expedite their progression, are identifiable by the expression of the myofibroblast marker $\alpha$-SMA. ${ }^{42}$ In contrast to Tis and T1 intestinal-type cancers, no T2 to T4 intestinal-type or any diffuse-type gastric cancer exhibited periglandular POSTN staining, but all exhibited stromal POSTN staining. In these tumors, increased fibroblast cellularity and $\alpha-\mathrm{SMA}^{+}$myofibroblasts were noted in a desmoplastic cancer stroma. Although the intestinal-type carcinoma involves and extends through the lamina propria mucosae, the tumor cells are exposed to the underlying stroma, in which there is increased stromal cellularity, an inflammatory cell infiltrate, and new vascularization. Little or no basement membrane exists in the diffuse-type gastric cancer cells. The tumor cells thus induce cancer-stromal interaction directly in the lamina propria mucosae and in the deeper layers of the gastric wall. Particularly, the linitis plastica type of diffuse gastric cancer, which contains scattered tumor cells and accumulated CAFs in desmoplastic fibrous stroma, showed intense stromal POSTN staining. These staining differences might explain the clinical behavior of the two gastric cancer types, with the diffuse type exhibiting more aggressive behavior than the intestinal type. ${ }^{24}$ POSTN is involved in the epithelial-mesenchymal transition (EMT), which is responsible for dissemination of primary tumor epithelial cells to the sites of metastasis. ${ }^{43}$ POSTN has been shown to be not only an EMT marker, but an EMT inducer. ${ }^{44}$ Our histological expression analyses strongly suggested that CAFs are the primary source of POSTN, which facilitates tumor cell invasion by inducing EMT and by establishing a neoplastic niche in gastric cancers.

POSTN exerts its protumorigenic effect through its binding to the integrins, $\alpha v \beta 3, \alpha v \beta 5$, and $\alpha 6 \beta 4$, promoting the recruitment of the epidermal growth factor receptor (EGFR) and the activation of the Akt/PKB and FAK-mediated signaling pathways. ${ }^{12,43} \mathrm{We}$ demonstrated the cancersupportive effects of POSTN in a diffuse-type gastric cancer cell line, OCUM-2MLN, with a supplement of the recombinant POSTN or by coculture of POSTN-overexpressing fibroblasts in vitro and in vivo. Furthermore, recombinant POSTN activated ERK signaling in OCUM-2MLN and
OCUM-12 cells. Using a diffuse-type gastric cancer orthotopic inoculation model, we demonstrated that host stromal cell-derived POSTN supported tumor cell growth. The tumors in Postn ${ }^{-1-}$ mice were significantly smaller than those in Postn ${ }^{+/+}$mice. More Ki-67 $7^{+}$and p-ERK ${ }^{+}$tumor cells were observed in the tumors inoculated into Postn ${ }^{+/+}$mice than in those inoculated into Postn ${ }^{-1-}$ mice. POSTN increased the ability to contract a collagen matrix ${ }^{45}$ which is a characteristic of myofibroblasts and CAFs. ${ }^{46}$ Such mechanical strains are known to trigger the release of the active form of TGF- $\beta 1$ from the stiff ECM in which the inactive form of TGF- $\beta 1$ is embedded. ${ }^{34,47}$ In addition, POSTN promotes incorporation of tenascin-C into the ECM to reinforce them. ${ }^{48}$ We therefore speculate that POSTN promotes stiffening of ECM in the cancer niche, thereby releasing the active form of TGF- $\beta 1$. This release can be expected to result in an accumulation of $\alpha$-SMA ${ }^{+}$CAFs secreting POSTN and inducing EMT and cancer cell proliferation. POSTNexpressing CAFs constitute a cancer-promoting microenvironment via regulation of cancer cell proliferation, in part, by triggering ERK signaling pathway, but also via indirect modification of ECM composition and growth factor activity in the cancer niche.

In conclusion, results of detailed bioinformatics and histological investigation showed that $\alpha-\mathrm{SMA}^{+} \mathrm{CAFs}$ produced POSTN in a desmoplastic stroma and formed the neoplastic niche in gastric cancer. POSTN promoted cancer cell growth via a signaling pathway involving ERK. Moreover, POSTN might facilitate EMT. With further understanding of cancer microenvironments, in which complex molecular networks exist among tumor cells and other components, POSTN is potentially an attractive therapeutic intervention target for cancer therapy.

\section{Acknowledgments}

We thank Kei Sakuma and Harumi Yamamura for technical assistance with histology.

Y.K., A.K., and T.G.K. conceived and conducted experiments. C.I., D.K., T.N., K.S., K.T., J.S., and Y.M. conducted experiments and generated data. D.K., J.I., I.K., M.Y., K.H., K.M., A.K., and M.F. interpreted data. All authors were involved in writing the manuscript and had final approval of the submitted and published versions.

\section{Supplemental Data}

Supplemental material for this article can be found at http://dx.doi.org/10.1016/j.ajpath.2013.11.012.

\section{References}

1. Malanchi I, Santamaria-Martínez A, Susanto E, Peng H, Lehr HA, Delaloye JF, Huelsken J: Interactions between cancer stem cells and their niche govern metastatic colonization. Nature 2011, 481:85-89 
2. Takeshita S, Kikuno R, Tezuka K, Amann E: Osteoblast-specific factor 2: cloning of a putative bone adhesion protein with homology with the insect protein fasciclin I. Biochem J 1993, 294:271-278

3. Horiuchi K, Amizuka N, Takeshita S, Takamatsu H, Katsuura M, Ozawa H, Toyama Y, Bonewald LF, Kudo A: Identification and characterization of a novel protein, periostin, with restricted expression to periosteum and periodontal ligament and increased expression by transforming growth factor beta. J Bone Miner Res 1999, 14: $1239-1249$

4. Kudo A: Periostin in fibrillogenesis for tissue regeneration: periostin actions inside and outside the cell. Cell Mol Life Sci 2011, 68: 3201-3207

5. Shimazaki M, Kudo A: Impaired capsule formation of tumors in periostin-null mice. Biochem Biophys Res Commun 2008, 367:736-742

6. Nishiyama T, Kii I, Kashima TG, Kikuchi Y, Ohazama A, Shimazaki M, Fukayama M, Kudo A: Delayed re-epithelialization in periostin-deficient mice during cutaneous wound healing. PLoS One 2011, 6:e18410

7. Segers VF, Lee RT: Protein therapeutics for cardiac regeneration after myocardial infarction. J Cardiovasc Transl Res 2010, 3:469-477

8. Sasaki H, Dai M, Auclair D, Fukai I, Kiriyama M, Yamakawa Y, Fujii Y, Chen LB: Serum level of the periostin, a homologue of an insect cell adhesion molecule, as a prognostic marker in nonsmall cell lung carcinomas [Erratum appeared in Cancer 2002, 95:2580]. Cancer 2001, 92:843-848

9. Gillan L, Matei D, Fishman DA, Gerbin CS, Karlan BY, Chang DD: Periostin secreted by epithelial ovarian carcinoma is a ligand for alpha(V)beta(3) and alpha(V)beta(5) integrins and promotes cell motility. Cancer Res 2002, 62:5358-5364

10. Grigoriadis A, Mackay A, Reis-Filho JS, Steele D, Iseli C, Stevenson BJ, Jongeneel CV, Valgeirsson H, Fenwick K, Iravani M, Leao M, Simpson AJ, Strausberg RL, Jat PS, Ashworth A, Neville AM, O'Hare MJ: Establishment of the epithelial-specific transcriptome of normal and malignant human breast cells based on MPSS and array expression data. Breast Cancer Res 2006, 8:R56

11. Shao R, Bao S, Bai X, Blanchette C, Anderson RM, Dang T, Gishizky ML, Marks JR, Wang XF: Acquired expression of periostin by human breast cancers promotes tumor angiogenesis through upregulation of vascular endothelial growth factor receptor 2 expression. Mol Cell Biol 2004, 24:3992-4003

12. Bao S, Ouyang G, Bai X, Huang Z, Ma C, Liu M, Shao R, Anderson RM, Rich JN, Wang XF: Periostin potently promotes metastatic growth of colon cancer by augmenting cell survival via the Akt/PKB pathway. Cancer Cell 2004, 5:329-339

13. Kikuchi Y, Kashima TG, Nishiyama T, Shimazu K, Morishita Y, Shimazaki M, Kii I, Horie H, Nagai H, Kudo A, Fukayama M: Periostin is expressed in pericryptal fibroblasts and cancer-associated fibroblasts in the colon. J Histochem Cytochem 2008, 56:753-764

14. Baril P, Gangeswaran R, Mahon PC, Caulee K, Kocher HM, Harada T, Zhu M, Kalthoff H, Crnogorac-Jurcevic T, Lemoine NR: Periostin promotes invasiveness and resistance of pancreatic cancer cells to hypoxia-induced cell death: role of the beta4 integrin and the PI3k pathway. Oncogene 2007, 26:2082-2094

15. Erkan M, Kleeff J, Gorbachevski A, Reiser C, Mitkus T, Esposito I, Giese T, Buchler MW, Giese NA, Friess H: Periostin creates a tumorsupportive microenvironment in the pancreas by sustaining fibrogenic stellate cell activity. Gastroenterology 2007, 132:1447-1464

16. Fukushima N, Kikuchi Y, Nishiyama T, Kudo A, Fukayama M: Periostin deposition in the stroma of invasive and intraductal neoplasms of the pancreas. Mod Pathol 2008, 21:1044-1053

17. Kanno A, Satoh K, Masamune A, Hirota M, Kimura K, Umino J, Hamada S, Satoh A, Egawa S, Motoi F, Unno M, Shimosegawa T: Periostin, secreted from stromal cells, has biphasic effect on cell migration and correlates with the epithelial to mesenchymal transition of human pancreatic cancer cells. Int J Cancer 2008, 122:2707-2718

18. Utispan K, Thuwajit P, Abiko Y, Charngkaew K, Paupairoj A, Chauin S, Thuwajit C: Gene expression profiling of cholangiocarcinoma- derived fibroblast reveals alterations related to tumor progression and indicates periostin as a poor prognostic marker. Mol Cancer 2010, 9:13

19. Kudo Y, Ogawa I, Kitajima S, Kitagawa M, Kawai H, Gaffney PM, Miyauchi M, Takata T: Periostin promotes invasion and anchorageindependent growth in the metastatic process of head and neck cancer. Cancer Res 2006, 66:6928-6935

20. Ferlay J, Shin HR, Bray F, Forman D, Mathers C, Parkin DM: Estimates of worldwide burden of cancer in 2008: GLOBOCAN 2008. Int J Cancer 2010, 127:2893-2917

21. Li JS, Sun GW, Wei XY, Tang WH: Expression of periostin and its clinicopathological relevance in gastric cancer. World J Gastroenterol 2007, 13:5261-5266

22. Liu Y, Liu BA: Enhanced proliferation, invasion, and epithelialmesenchymal transition of nicotine-promoted gastric cancer by periostin. World J Gastroenterol 2011, 17:2674-2680

23. Lauren P: The two histological main types of gastric carcinoma: diffuse and so-called intestinal-type carcinoma. An attempt at a histoclinical classification. Acta Pathol Microbiol Scand 1965, 64:31-49

24. Hu B, El Hajj N, Sittler S, Lammert N, Barnes R, Meloni-Ehrig A: Gastric cancer: Classification, histology and application of molecular pathology. J Gastrointest Oncol 2012, 3:251-261

25. Hubbell E, Liu WM, Mei R: Robust estimators for expression analysis. Bioinformatics 2002, 18:1585-1592

26. Subramanian A, Tamayo P, Mootha VK, Mukherjee S, Ebert BL, Gillette MA, Paulovich A, Pomeroy SL, Golub TR, Lander ES, Mesirov JP: Gene set enrichment analysis: a knowledge-based approach for interpreting genome-wide expression profiles. Proc Natl Acad Sci USA 2005, 102:15545-15550

27. Vastrik I, D'Eustachio P, Schmidt E, Gopinath G, Croft D, de Bono B, Gillespie M, Jassal B, Lewis S, Matthews L, Wu G, Birney E, Stein L: Reactome: a knowledge base of biologic pathways and processes. Genome Biol 2007, 8:R39

28. Ashburner M, Ball CA, Blake JA, Botstein D, Butler H, Cherry JM, Davis AP, Dolinski K, Dwight SS, Eppig JT, Harris MA, Hill DP, Issel-Tarver L, Kasarskis A, Lewis S, Matese JC, Richardson JE, Ringwald M, Rubin GM, Sherlock G: Gene ontology: tool for the unification of biology. The Gene Ontology Consortium. Nat Genet 2000, 25:25-29

29. Fujihara T, Sawada T, Hirakawa K, Chung YS, Yashiro M, Inoue T, Sowa M: Establishment of lymph node metastatic model for human gastric cancer in nude mice and analysis of factors associated with metastasis. Clin Exp Metastasis 1998, 16:389-398

30. Kii I, Amizuka N, Minqi L, Kitajima S, Saga Y, Kudo A: Periostin is an extracellular matrix protein required for eruption of incisors in mice. Biochem Biophys Res Commun 2006, 342:766-772

31. Acuff HB, Carter KJ, Fingleton B, Gorden DL, Matrisian LM: Matrix metalloproteinase-9 from bone marrow-derived cells contributes to survival but not growth of tumor cells in the lung microenvironment. Cancer Res 2006, 66:259-266

32. Kashima TG, Nishiyama T, Shimazu K, Shimazaki M, Kii I, Grigoriadis AE, Fukayama M, Kudo A: Periostin, a novel marker of intramembranous ossification, is expressed in fibrous dysplasia and in c-Fos-overexpressing bone lesions. Hum Pathol 2009, 40:226-237

33. Contié S, Voorzanger-Rousselot N, Litvin J, Clézardin P, Garnero P: Increased expression and serum levels of the stromal cell-secreted protein periostin in breast cancer bone metastases. Int $\mathrm{J}$ Cancer 2011, 128:352-360

34. Otranto M, Sarrazy V, Bonté F, Hinz B, Gabbiani G, Desmoulière A: The role of the myofibroblast in tumor stroma remodeling. Cell Adh Migr 2012, 6:203-219

35. Zang ZJ, Ong CK, Cutcutache I, Yu W, Zhang SL, Huang D, Ler LD, Dykema K, Gan A, Tao J, Lim S, Liu Y, Futreal PA, Grabsch H, Furge KA, Goh LK, Rozen S, Teh BT, Tan P: Genetic and structural variation in the gastric cancer kinome revealed through targeted deep sequencing. Cancer Res 2011, 71:29-39

36. Corren J, Lemanske RF, Hanania NA, Korenblat PE, Parsey MV, Arron JR, Harris JM, Scheerens H, Wu LC, Su Z, Mosesova S, 
Eisner MD, Bohen SP, Matthews JG: Lebrikizumab treatment in adults with asthma. N Engl J Med 2011, 365:1088-1098

37. Masuoka M, Shiraishi H, Ohta S, Suzuki S, Arima K, Aoki S, Toda S, Inagaki N, Kurihara Y, Hayashida S, Takeuchi S, Koike K, Ono J, Noshiro H, Furue M, Conway SJ, Narisawa Y, Izuhara K: Periostin promotes chronic allergic inflammation in response to Th2 cytokines. J Clin Invest 2012, 122:2590-2600

38. Takayama G, Arima K, Kanaji T, Toda S, Tanaka H, Shoji S, McKenzie AN, Nagai H, Hotokebuchi T, Izuhara K: Periostin: a novel component of subepithelial fibrosis of bronchial asthma downstream of IL-4 and IL-13 signals. J Allergy Clin Immunol 2006, 118:98-104

39. Fennell RH Jr, Castleman B: Carcinoma in situ. N Engl J Med 1955, 252:1032-1037

40. Dixon MF: Gastrointestinal epithelial neoplasia: Vienna revisited. Gut 2002, 51:130-131

41. Mutoh H, Sakurai S, Satoh K, Osawa H, Hakamata Y, Takeuchi T, Sugano K: Cdx1 induced intestinal metaplasia in the transgenic mouse stomach: comparative study with Cdx2 transgenic mice. Gut 2004, 53: $1416-1423$

42. Kalluri R, Zeisberg M: Fibroblasts in cancer. Nat Rev Cancer 2006, 6: 392-401
43. Morra L, Moch H: Periostin expression and epithelial-mesenchymal transition in cancer: a review and an update. Virchows Arch 2011, 459: 465-475

44. Yan W, Shao R: Transduction of a mesenchyme-specific gene periostin into 293 T cells induces cell invasive activity through epithelial-mesenchymal transformation. J Biol Chem 2006, 281:19700-19708

45. Elliott CG, Wang J, Guo X, Xu SW, Eastwood M, Guan J, Leask A, Conway SJ, Hamilton DW: Periostin modulates myofibroblast differentiation during full-thickness cutaneous wound repair. J Cell Sci 2012, 125:121-132

46. Orimo A, Gupta PB, Sgroi DC, Arenzana-Seisdedos F, Delaunay T, Naeem R, Carey VJ, Richardson AL, Weinberg RA: Stromal fibroblasts present in invasive human breast carcinomas promote tumor growth and angiogenesis through elevated SDF-1/CXCL12 secretion. Cell 2005, 121:335-348

47. Horiguchi M, Ota M, Rifkin DB: Matrix control of transforming growth factor- $\beta$ function. J Biochem 2012, 152:321-329

48. Kii I, Nishiyama T, Li M, Matsumoto K, Saito M, Amizuka N, Kudo A: Incorporation of tenascin-C into the extracellular matrix by periostin underlies an extracellular meshwork architecture. J Biol Chem 2010, 285:2028-2039 